\title{
Determinants of early days of newborn feeding mal- practice among mothers of children less than one years of age in Mizan-Aman Town, South-west Ethiopia, 2020
}

Muluken Amare ( $\nabla$ 385mule@gmail.com )

Wollo University

Research

Keywords: suboptimal breast-feeding, prelacteal feeding, colostrum avoidance

Posted Date: October 29th, 2020

DOI: https://doi.org/10.21203/rs.3.rs-97878/v1

License: (9) This work is licensed under a Creative Commons Attribution 4.0 International License.

Read Full License 


\section{Abstract}

Back ground: Neonatal death remained a global public health issue, especially in Ethiopia due to suboptimal breast-feeding practices. While several interventions have been made to comply with the WHO guideline, sub-optimal feeding practices are commonly seen in Ethiopia. The goal of this study was therefore to identify gaps in optimal breast-feeding practice in South West Ethiopia.

Objective: To assess the prevalence and determinant of early days of newborn feeding mal-practices among recently delivered women in Mizan-Aman Town, southwestern Ethiopia, 2020.

Methods: A community-based cross-sectional study was undertaken on recently delivered women from March-April/2020. A total of 487 mothers-child ( $<12$ month) pair were selected by using multistage randomized sampling technique and the data was collected through face to face interview by using structured questionnaire. The result was analyzed via SPSS version 26. Multivariate logistic regression analysis was used to assess determinant of newborn feeding mal-practices and a $p<0.05$ was deem to be significant.

Result: Prevalence of prelacteal feeding and colostrum avoidance was approximately $21.9 \%$ and $15.5 \%$ respectively. The most common prelacteal food was Rue / Tenadam/49 (10.1\%). The key reasons were: 49(10.1 \%) Cultural activity followed by 45 (9.3 \%) clean-up of the intestine / throat / mouth of babies. Determinants of pre-lacteal feeding were found to be: mothers recognizing risks of prelacteal feeding, multipara mothers, having $\geq 4$ number of children and infant's birth order 4-6. Likewise, exposure to infant formula advertisement, absence of home to home health education, multipara mothers and spontaneous vaginal birth were the determinants of colostrum avoidance.

Conclusion: The study found that there was a sub-optimal breast-feeding practice, one in four newborns. As a result, activities to discourage pre-lacteal feeding and to improve early initiation of colostrum feeding practices shall be carried out.

\section{Introduction}

Breast milk is a fundamental right, nutritious, has an optimum temperature, does not require any preparation and is easily accessible to infant food [1]. Colostrum is the first milk, yellowish in color, thick and produced just 3-4 days after birth. It provides all the essential nutrients for baby growth and wellbeing, immune factors and helps the newborn to get through meconium. As such, colostrum is considered to be the first and infant immunization [2].

Exercising optimal breast-feeding benefits both infants and mothers. It protects the infant from acquiring infectious morbidity and mortality, overweight, diabetes and chronic disease as well as can prevent mothers breast cancer, better birth spacing, reduce the risk of diabetes and ovarian cancer. Therefore, making the breast-feeding practice to universal level, could save about 823,000 child death and 20,000 breast cancer death every year [3]. 
Despite the recommendation of the World Health Organization (WHO) that early initiation of colostrum feeding and exclusive breastfeeding as a golden standard for early infant feeding, about 78 million newborns worldwide waited for more than one hour to breastfeed, two out of five newborns were given fluids or solids other than breast milk and excluded from colostrum feeding in the early days of their life[4, 5].

Globally, neonatal death has remained the lion share of (45\%) among all under-five deaths in 2018[6]. Similarly, every day, about 4,000 infants and young children die due to Colostrum avoidance and introduction of prelacteal feds, worldwide [7]. As a result, many infants suffer from insufficient breast milk, lactation failure and insufficient weight gain. Likewise, $45 \%$ of neonatal infectious deaths, $30 \%$ of diarrheal deaths and $18 \%$ of acute respiratory deaths among under five children associated with inappropriate feeding practices $[8,9,10]$.

While Ethiopia has a strong experience in early initiation of colostrum feeding (73.3\%), it does not always comply with WHO / UNICEF recommendations [4]. At the national level, one in four infants (25.29 per cent) received pre-lacteal feed during the first three days of life [11] and colostrum avoidance practices ranged from $6.3 \%$ up to $67.2 \%$ in Tigray Aksum and Meshenti, north west Ethiopia [12, 13]. As a result, $18 \%$ of infant deaths could be due to suboptimal breastfeeding practices [14].

Studies conducted in Ethiopia have shown that there are multifactorial determinants of early newborn feeding mal-practices such as: sociodemographic factors, home and caesarean section delivery, low level of breastfeeding information, lack of postnatal care and breast-feeding advice $[11,12,15,16]$.

Since 2004, Ethiopia has adapted the Guideline for Infant and Young Child Feeding Practices (IYCF) [17] and the 2013 National Nutrition Policy to promote optimal breastfeeding practices through multi-sectoral integration [18]. While remarkable advances have been made with regard to the optimal promotion of breast-feeding at the facility and at the community extent, the level of current practice is not well recorded in the study area. The goal of this study was therefore to assess the magnitude and determinants of prelacteal feeding among recently delivered mothers in Mizan-Aman Town, southwestern Ethiopia.

\section{Methods And Materials}

\section{Study area and period}

The study was conducted from 3 March to 3 April 2020 in the town of Mizan-Aman, the capital of the Bench Sheko zone. The town is situated $561 \mathrm{~km}$ from Addis Ababa, administratively structured by five kebeles and has a total population of 49,590, of which 11,554 are women in the 15-49 age group and 1,582 are children under the age of one. The key economic activity in the town is cash crop farming and gold mining. It has one hospital, a health center, and three health posts.

\section{Study Design And Population}


A community-based cross-sectional study was employed. Mothers of children less than one years of age that are living in randomly selected kebeles were considered as study population.

\section{Sampling Procedures And Size}

The sample size was determined using a single population proportion formula, assuming a 50 percent, 95 percent $\mathrm{Cl}, 5$ percent marginal error prevalence for prelacteal feeding. Correction formula was used since the source of population was $<10,000$, and the sample was multiplied by a design effect of 1.5 and finally, the final sample size was 487 by adding 5 percent non-response rate. Multi-stage randomized sampling technique was used to capture participants in the sample. The town of Mizan-Aman has two sub-city and five kebeles. The sub-city of Mizan has 3 kebeles and the sub-city of Aman has 2 kebeles. Of these, a total of 3 kebeles were selected using the lottery process. In order to achieve the sample size of each 3 kebeles, a proportional allocation to the size was made Following the sampling fraction / interval, the mother / child pair was chosen on a three-house basis using systematic random sampling by reference to the community health extension worker family record book as a sampling frame.

\section{Operational Definition}

Prelacteal feeding; is defined as giving fluid or semisolid before breast feeding to an infant during the first three days after birth [19].

Colostrum avoidance; includes; pumping and discarding colostrum during the first five days after birth [19].

\section{Data Collection}

The tool was adapted from the 2016 Ethiopian Demographic and Health Survey (EDHS) document [19] and structured questionnaires were used to collect data via face-to - face interviews. The questionnaire was first prepared in English, translated into Amharic. Data quality was ensured by hiring nurse practitioners as data collectors, offering preparation for data collectors and conducting pre-tests in $5 \%$ of the sample size of the mother / child pair in Debrework Area.

\section{Data Analysis}

The data was washed, encoded and entered in Epi Info version 3.5.3 and exported to SPSS version 26 of the statistical package for analysis. Descriptive statistics have been computed to determine the magnitude of the suboptimal breast-feeding practice. In addition, a bivariate logistic regression technique has been used. Subsequently, these variables with $p<0.2$ were shifted to a multivariate analysis and evaluated using a stepwise multivariate logistic regression technique to monitor the effects of confounding and to classify predictors of suboptimal breast-feeding practices. A P-value of $<0.05$ was found to be statistical significance at a $95 \%$ confidence interval.

\section{Result}




\section{Socio-demographic characteristics of the respondents}

A total of 487 mother-to -child pairs were included in the study, resulting in a response rate of 485 (99.6\%). The majority of women, 184 (37.9\%), were 20-24 years of age and the mean ( \pm SD) age of mothers was 24.5 ( \pm 5.5 ) years of age. In addition, of the total respondents, 459 (94.6 per cent) were married, 291 ( 60 per cent) had a family size $\geq 4,284$ (58.6 per cent) were housewives by occupation, and 167 (34.4 per cent) attended primary school. Moreover, about 229(47.2\%) of infants were first-order / firstchild for their family (Table 1 ). 
Table 1

Socio-demographic characteristics of mothers of children aged less than one years in Mizan-Aman town, south west Ethiopia, 2020 ( $N=485)$

\begin{tabular}{|c|c|c|}
\hline Demographic variable & Frequency $(\mathrm{N}=485)$ & Percentage (\%) \\
\hline \multicolumn{3}{|l|}{ Family size } \\
\hline$<=3$ & 194 & 40.0 \\
\hline$>4$ & 291 & 60.0 \\
\hline \multicolumn{3}{|l|}{ Age of mothers } \\
\hline $15-19$ & 51 & 10.5 \\
\hline $20-24$ & 184 & 37.9 \\
\hline $25-29$ & 162 & 33.4 \\
\hline$>30$ & 88 & 18.1 \\
\hline \multicolumn{3}{|l|}{ Maternal marital status } \\
\hline Single & 20 & 4.1 \\
\hline Married & 459 & 94.6 \\
\hline Other & 6 & 1.2 \\
\hline \multicolumn{3}{|l|}{ Maternal educational level } \\
\hline Informal education & 142 & 29.3 \\
\hline Primary $(1-8)$ & 167 & 34.4 \\
\hline Secondary $(9-12)$ and above & 176 & 36.2 \\
\hline \multicolumn{3}{|l|}{ Maternal religion } \\
\hline Orthodox & 192 & 39.6 \\
\hline Protestant & 179 & 36.9 \\
\hline Muslim & 114 & 23.5 \\
\hline \multicolumn{3}{|l|}{ Maternal occupation } \\
\hline government employee & 58 & 12.0 \\
\hline house wife & 284 & 58.6 \\
\hline Others & 143 & 29.4 \\
\hline \multicolumn{3}{|l|}{ Birth order of the infant } \\
\hline First & 229 & 47.2 \\
\hline
\end{tabular}




\begin{tabular}{|lll|}
\hline Demographic variable & Frequency $(\mathrm{N}=485)$ & Percentage $(\%)$ \\
\hline$>=2$ & 256 & 52.7 \\
\hline No of children in the family & & \\
$<=3$ & 424 & 87.4 \\
$>=4$ & 61 & 12.6 \\
\hline
\end{tabular}

\section{Obstetrics And Maternal Health Service Utilization}

The majority, $249(51.3 \%)$ of mothers were multipara, $470(96.9 \%)$ of the women were attending ANC, $315(67 \%)$ of them utilized ANC four and more times, while $280(59.6 \%)$ of them had gotten breast feeding counseling at the ANC clinic. Besides, $434(89.5 \%)$ of the study participants delivered their child at a government health facility and their delivery was assisted by skilled birth attendant and $435(89.7 \%)$ delivered through normal spontaneous (Table 2). 
Table 2

; Health service utilization among mothers of children less than one years of age in Mizan-Aman town, $2020(\mathrm{~N}=485)$

\begin{tabular}{|c|c|c|}
\hline Variables & Frequency $(\mathrm{N}=485)$ & Percentage $(\%)$ \\
\hline \multicolumn{3}{|l|}{ Attending Antenatal care $(n=485)$} \\
\hline Yes & 470 & 96.9 \\
\hline No & 15 & 3.1 \\
\hline \multicolumn{3}{|c|}{ Frequency of Antenatal care $(n=470)$} \\
\hline 1 time & 11 & 2.3 \\
\hline $2-3$ times & 144 & 30.6 \\
\hline$\geq 4$ & 315 & 67.0 \\
\hline \multicolumn{3}{|c|}{ Get breast feeding Counseling at ANC Clinic $(n=470)$} \\
\hline Yes & 280 & 59.6 \\
\hline No & 190 & 40.4 \\
\hline \multicolumn{3}{|l|}{ Place of Delivery $(n=485)$} \\
\hline Gov't Health Facility & 434 & 89.5 \\
\hline Private Clinic & 2 & .4 \\
\hline At Home & 48 & 9.9 \\
\hline TBAs Place & 1 & .2 \\
\hline \multicolumn{3}{|l|}{ Mode of Delivery $(n=485)$} \\
\hline CS Delivery & 49 & 10.1 \\
\hline Normal Spontaneous Delivery & 435 & 89.7 \\
\hline Instrumental delivery & 1 & .2 \\
\hline \multicolumn{3}{|l|}{ Delivery Attendant( $n=485)$} \\
\hline Health Professionals & 435 & 89.7 \\
\hline Traditional Birth Attendants & 50 & 10.3 \\
\hline
\end{tabular}

The majority of mothers were multiparous, $249(51.3 \%), 470(96.9 \%)$ of women attended ANC, $315(67 \%)$ of them used ANC four and more times, while at the ANC clinic, 280(59.6\%) of them had received breast feeding counseling. In addition, 434 (89.5\%) of the study participants delivered their child at a 
government health facility and were assisted by skilled birth attendants and delivered $435(89.7 \%)$ by usual spontaneous delivery.

\section{Colostrum Avoidance Practice}

Although all mothers have breastfed ever their current infant, 163(35.5\%) newborns were put to the breast more than one hour and $75(15.5 \%)$ of women were discarded colostrum for their infants within the first five days after birth. The main reasons for colostrum avoidance were; breast feeding problem 50(10.3\%), maternal medical illness 19(3.9\%) and a reason for their child health 6(1.23\%) (Table 3).

Table 3

Colostrum avoidance among mothers of children's less than one years of age, Mizan-Aman town, 2020( $\mathrm{N}=485)$

\begin{tabular}{|lll|}
\hline Variables & Frequency(N =485) & Percent \\
\hline Breastfed ever their current infant & & \\
\hline Yes & 485 & 100 \\
\hline Initiation of breast-feeding & & \\
\hline$<1$ hour & 296 & 64.5 \\
\hline$>1$ hour & 163 & 35.5 \\
\hline colostrum avoidance & & \\
\hline Yes & 75 & 15.5 \\
\hline No & 410 & 84.5 \\
\hline Reason for colostrum avoidance & & 10.3 \\
\hline Breast feeding problem & 50 & 3.9 \\
\hline Maternal medical illness & 19 & 1.23 \\
\hline For baby's health & 6 & \\
\hline
\end{tabular}

\section{Prelacteal Feeding Practice}

Of the total respondents, within the first three days after birth, 106(21.9\%) were given prelacteal feds other than breast feed for their babies. Water with "Tenadam"/rue 49(10.1\%), followed by plain water 33(6.8\%), glucose with water $10(2.1 \%)$ and formula milk $9(1.9 \%)$ were the most popular types of prelacteal food. The main reasons for pre-lacteal feeding were: $49(10.1 \%)$ cultural practice, $45(9.3 \%)$ intestinal / throat / mouth cleanse, 31(6.4 per cent) due to breast feeding problems, and 19(3.9\%) mothers believed that newborn breast feeding would be thirsty. (Table 4). 
Table 4

prelacteal feeding among mothers of children's less than one years of age, Mizan-Aman town, 2020( $\mathrm{N}=485)$

\begin{tabular}{|lll|}
\hline Variables & Frequency & Percent \\
\hline Prelacteal feeding & & \\
\hline Yes & 106 & 21.9 \\
\hline No & 379 & 78.1 \\
\hline Type of prelacteal food & & \\
\hline Water and Tenadam/rue & 49 & 10.1 \\
\hline Plain water & 33 & 6.8 \\
\hline sugar with water & 10 & 2.1 \\
\hline Formula milk & 9 & 1.9 \\
\hline Butter & 5 & 1 \\
\hline Reasons for prelacteal feeding were & & \\
\hline Cultural practice & 49 & 10.1 \\
\hline To clean infants' bowel/throat/mouth & 45 & 9.3 \\
\hline Breast feeding problem & 31 & 6.4 \\
\hline Mothers believed that breast feed for new born will be thirsty & 19 & 3.9 \\
\hline For infant health & 14 & 2.9 \\
\hline Maternal medical illness & 11 & 2.3 \\
\hline To calm/soothe the baby & 9 & 1.9 \\
\hline
\end{tabular}

As for guidance on offering this form of pre-lacteal feeding; their own decision was a dominant factor, $51(10.5 \%)$, followed by grandparents; $28(5.8 \%)$, their friends; $15(3.1 \%)$, most recently health professionals; 8(1.6\%) (Fig. 1).

\section{Factor Associated With Prelacteal Feeding}

According to the bivariate logistic regression analysis, the following study variables were significantly associated with pre-lacteal feeding $(p<0,05)$ : mothers in age groups $20-24$ years old and 35-39 years old, mothers in income $>1,500 \mathrm{birr} /$ month, infants in birth order 4-6, multipara mothers, mothers assisted by traditional birth attendants and mothers who understood the risk of prelacteal feeding 
In addition, these variables with $p<0.2$ from the bivariate analysis were evaluated using a multivariate analysis. As a result, multivariate logistic regression analysis; multipara mothers, infants' birth in order 46 , having $\geq 4$ children and mothers who understood the risk of pre-lacteal feeding were determinants of pre-lacteal feeding. Multipara Mothers were 3.56(AOR: 95\% Cl: 1.036, 12.227) times more likely to give prelacteal feds when compared to the counterpart. The odds of prelacteal feeding among mothers who knew the risk of prelacteal feeding were almost seven times, (AOR $=6.91,95 \% \mathrm{Cl}$ : 3.002, 15.904), higher than the counterpart. Furthermore, infant's birth order between 4-6 were 12.28(AOR: 95\% Cl: 1.528 , 98.639) times more likely to give prelacteal feeding when compared to infant's birth order one. The odds of prelacteal feeding among mothers having $\geq 4$ number of children were nearly five times, $(A O R=5.2$, $95 \% \mathrm{Cl}$ : $1.033,26.141)$, higher than, those mothers having $\leq 3$ number of children (Table 5 ). 
Table 5

Factors associated with prelacteal feeding practices among mothers of children aged less than 12month in Mizan-Aman town, 2020

\begin{tabular}{|c|c|c|c|c|}
\hline \multirow[t]{2}{*}{ Variable } & \multicolumn{2}{|c|}{ Prelacteal feeding } & \multirow[t]{2}{*}{ Crude OR (Cl: 95\%) } & \multirow{2}{*}{$\begin{array}{l}\text { Adjusted OR (Cl: } \\
95 \%)\end{array}$} \\
\hline & Yes (\%) & No $(\%)$ & & \\
\hline \multicolumn{5}{|l|}{ Age } \\
\hline $15-19$ & $21(41.2)$ & $30(58.8)$ & 1 & 1 \\
\hline $20-24$ & $40(21.7)$ & 144(78.3) & $2.52(1.304,4.869)$ * & $.626(.174,2.26)$ \\
\hline $25-29$ & $26(16)$ & 136(84) & $3.66(1.82,7.357)$ & $.983(.237,4.071)$ \\
\hline $30-34$ & $13(25.5)$ & $38(74.5)$ & $2.046(.882,4.745)$ & $.208(.032,1.351)$ \\
\hline $35-39$ & $6(19.4)$ & $25(80.6)$ & $2.917(1.019,8.344)$ * & $.856(.08,9.125)$ \\
\hline \multicolumn{5}{|l|}{ Income } \\
\hline$<500 \mathrm{~B} /$ month & $77(24.3)$ & $240(75.7)$ & 1 & 1 \\
\hline $500-1000 \mathrm{Br} /$ month & $18(22.5)$ & $62(77.5)$ & $1.105(.616,1.982)$ & $.677(.223,2.061)$ \\
\hline $1001-1500 \mathrm{Br} /$ month & $5(26.3)$ & 14(73.7) & $.898(.313,2.575)$ & $.25(.045,1.39)$ \\
\hline > $1500 \mathrm{Br} /$ month & $6(8.7)$ & 63(91.3) & $3.369(1.403,8.088)$ * & $1.224(.321,4.678)$ \\
\hline \multicolumn{5}{|l|}{ Birth order of infant } \\
\hline Birth order 1 & $58(25.3)$ & $171(74.7)$ & 1 & 1 \\
\hline Birth order 2-3 & $41(20.8)$ & $156(79.2)$ & $1.291(.819,2.034)$ & $2.568(.696,9.473)$ \\
\hline Birth order 4-6 & $5(9.8)$ & $46(90.2)$ & $3.12(1.183,8.23)$ * & ${ }_{\star \star}^{12.276}(1.528,98.639)$ \\
\hline \multicolumn{5}{|l|}{ NO_ of children } \\
\hline$\leq 3$ & $98(23.1)$ & $326(76.9)$ & 1 & 1 \\
\hline$\geq 4$ & $8(13.1)$ & 53(86.9) & 1.992(.916,4.331) & $\underset{\star \star}{5.197}(1.033,26.141)$ \\
\hline \multicolumn{5}{|l|}{ Parity } \\
\hline Primipara & $61(25.8)$ & $175(74.2)$ & 1 & 1 \\
\hline Multipara & $45(18.1)$ & 204(81.9) & $1.58(1.023,2.441)$ * & $\underset{* \star}{3.558(1.036,12.227)}$ \\
\hline
\end{tabular}

Statistically significant at $p<0.05$ in bivariate analysis and ** Statistically significant at $p<0.05$ in multivariate analysis 


\begin{tabular}{|c|c|c|c|c|}
\hline \multirow[t]{2}{*}{ Variable } & \multicolumn{2}{|c|}{ Prelacteal feeding } & \multirow[t]{2}{*}{ Crude OR (Cl: 95\%) } & \multirow{2}{*}{$\begin{array}{l}\text { Adjusted OR (Cl: } \\
95 \%)\end{array}$} \\
\hline & Yes (\%) & No (\%) & & \\
\hline Health professional & $87(20)$ & $348(80)$ & 1 & 1 \\
\hline Traditional birth attendant & 19(38) & $31(62)$ & $2.452(1.322,4.546)$ * & $1.668(.436,6.379)$ \\
\hline \multicolumn{5}{|l|}{$\begin{array}{l}\text { Mother knows demerits of } \\
\text { PLF }\end{array}$} \\
\hline Yes & $17(5.7)$ & $280(94.3)$ & ${ }_{\star}^{14.807(8.398,26.108)}$ & ${ }_{\star \star}^{6.909}(3.002,15.904)$ \\
\hline No & $89(47.3)$ & $99(52.7)$ & 1 & 1 \\
\hline
\end{tabular}

\section{Factors Associated With Colostrum Avoidance}

In the bivariate logistic regression, the following were; mothers found in age group of 20-24 years old and 25-29 years old, infant birth order between 2-3, having $\geq 4$ number of children, being multipara mothers, spontaneous vaginal delivery, having exposure to infant formula advertisement and not having home to home health education statistically significant with colostrum avoidance.

Accordingly, in multivariate logistic regression analysis; having exposure to infant formula advertisement, not having home to home health education, being multipara mothers and delivered through spontaneous vaginal delivery were determinants of colostrum avoidance. The odds of colostrum avoidance among mothers who have exposure to infant formula advertisement were nearly seven times, (AOR $=7.476,95 \%$ Cl: $3.549,15.752)$, higher than the counterpart. Likewise, the odds of colostrum avoidance among mothers who do not have home to home health education were nearly five times, $(A O R=5.474,95 \% \mathrm{Cl}$ : $2.876,10.419)$, higher than the counterpart. Moreover, multipara mothers were $10.045(\mathrm{AOR}: 95 \% \mathrm{Cl}$ : $1.456,19.289)$ times more likely to practice colostrum avoidance when compared to primipara mothers. The odds of colostrum avoidance among mothers who gave birth through spontaneous vaginal delivery were three times, (AOR: 95\% Cl: 1.245, 7.750), higher than, those mothers who gave birth through CS (Table 6). 
Table 6

Factors associated with colostrum avoidance practices among mothers of children aged less than 12 month in Mizan-Aman town, 2020

\begin{tabular}{|c|c|c|c|c|}
\hline \multirow[t]{2}{*}{ variables } & \multicolumn{2}{|c|}{ Colostrum avoidance } & \multirow[t]{2}{*}{ Crude OR (Cl: 95\%) } & \multirow{2}{*}{$\begin{array}{l}\text { Adjusted OR (Cl: } \\
95 \%)\end{array}$} \\
\hline & Yes (\%) & No $(\%)$ & & \\
\hline \multicolumn{5}{|l|}{ Age of respondents } \\
\hline $15-19$ & $16(21.3 \%)$ & $35(8.5 \%)$ & 1 & 1 \\
\hline $20-24$ & $25(33.3 \%)$ & $159(38.8 \%)$ & $2.97(1.406,6.012)$ * & $1.447(.584,3.581)$ \\
\hline $25-29$ & $20(26.7 \%)$ & $142(34.6 \%)$ & $3.246(1.527,6.901)$ * & $1.210(.436,3.363)$ \\
\hline $30-34$ & $11(14.7 \%)$ & $40(9.8 \%)$ & 1.662(.681,4.055) & $.163(.039, .671)$ \\
\hline $35-39$ & $3(4 \%)$ & $28(6.8 \%)$ & $\underset{*}{4.267(1.1 .29,16.124)}$ & $.229(.035,1.495)$ \\
\hline \multicolumn{5}{|l|}{ Infant birth order } \\
\hline Infant birth order 1 & $43(57.3 \%)$ & $186(45.4 \%)$ & 1 & 1 \\
\hline Infant birth order 2-3 & $31(41.3 \%)$ & $166(40.5 \%)$ & $1.238(.746,2.055)$ & $.211(.032,1.385)$ \\
\hline Infant birth order 4-6 & $1(1.3 \%)$ & $50(12.2 \%)$ & ${ }_{*}^{11.559(1.553,16.016)}$ & $4.375(.235,19.927)$ \\
\hline \multicolumn{5}{|l|}{ NO_ of children } \\
\hline$\leq 3$ & $74(98.7 \%)$ & $350(85.4 \%)$ & 1 & 1 \\
\hline$\geq 4$ & $1(1.3 \%)$ & $60(14.6 \%)$ & $\begin{array}{l}12.688(1.730,32.996) \\
*\end{array}$ & $4.335(.052,16.505)$ \\
\hline \multicolumn{5}{|l|}{ Parity } \\
\hline Primipara & $46(61.3 \%)$ & $190(46.3 \%)$ & 1 & 1 \\
\hline Multipara & $29(38.7 \%)$ & $220(53.7 \%)$ & $1.837(1.11,3.039)$ * & $\underset{\star \star}{10.045(1.456,19.289)}$ \\
\hline \multicolumn{5}{|l|}{ Mode of delivery } \\
\hline CS & $13(17.3 \%)$ & $36(8.8 \%)$ & 1 & 1 \\
\hline Spontaneous vaginal & $62(82.7 \%)$ & $373(91 \%)$ & 2.17291.091,4.326) * & $3.106(1.245,7.750)$ ** \\
\hline \multicolumn{5}{|l|}{$\begin{array}{l}\text { Home to home } \\
\text { education }\end{array}$} \\
\hline yes & $52(69.3 \%)$ & $77(18.8 \%)$ & 1 & 1 \\
\hline
\end{tabular}

Statistically significant at $p<0.05$ in bivariate analysis and ** Statistically significant at $p<0.05$ in multivariate analysis 


\begin{tabular}{|c|c|c|c|c|}
\hline \multirow[t]{2}{*}{ variables } & \multicolumn{2}{|c|}{ Colostrum avoidance } & \multirow[t]{2}{*}{ Crude OR (Cl: 95\%) } & \multirow{2}{*}{$\begin{array}{l}\text { Adjusted OR (Cl: } \\
95 \%)\end{array}$} \\
\hline & Yes (\%) & No (\%) & & \\
\hline no & $23(30.7 \%)$ & $338(81.2 \%)$ & $\underset{\star}{9.778(5.642,16.944)}$ & $\underset{\star \star}{5.47492 .876,10.419)}$ \\
\hline \multicolumn{5}{|c|}{$\begin{array}{l}\text { Exposure to infant } \\
\text { formula advertisement }\end{array}$} \\
\hline yes & $14(18.7 \%)$ & $283(69 \%)$ & $\underset{\star}{9.709}(5.237,18.002)$ & $\underset{\star \star}{7.476}(3.549,15.752)$ \\
\hline no & $61(81.3 \%)$ & $122(31 \%)$ & 1 & 1 \\
\hline
\end{tabular}

\section{Discussion}

This study found that breastfeeding activities were sub-optimal in the setting of the study due to the widespread implementation of prelacteal feds and colostrum prevention. The prelacteal feeding and colostrum-avoidance prevalence is found to be $21.9 \%$ and $15.5 \%$, respectively, in Mizan-Aman-town.

Prevalence of prelacteal feeding in this study was relatively comparable with studies in Wolayta sodo (20.6\%), Tigray (24.7\%) and Dabat district $(26.8 \%)[16,20,21]$. However, the figure we have obtained are far higher than those found in other studies in Sidama (5.5\%), in Mettu (14.2\%) and in Debrebirhan $(14.2 \%)[22,23,24]$. The observed variance may be due to variations in culture, health service access and population character. The figures we have obtained are much lower than those found in other studies in South Sudan (53\%), Vietnam (73.3\%), Egypt (58\%), Amhara (47.2\%) and the Harare region (43.5\%) [25, 26, $27,19,28]$. This may be due to religious and cultural traditions that have a lion's share in the provision of pre-lacteal food in the regions mentioned above, most of which have been in rural areas. In addition, in the early days of infants, the effects of grandparents would be greater.

The magnitude of colostrum-avoidance in this analysis was consistent with studies in Raya Kobo district (13.5\%), Tigray district (15\%) and Mettu, southwestern Ethiopia (17.5\%) $[29,20,23]$. While colostrum avoidance practice is higher in Mizan-Aman than in Aksum City (6.3\%), Wolayta Sodo (8.5\%) and Kombolicha City $(11.4 \%)[12,16,30]$. This distinction may be attributed to the use of socio-cultural, maternal health care programs and the number of institutional deliveries. The figure we have obtained is much smaller than that seen in other studies in Dabat, Northwest Ethiopia (47.1\%), Debrebirhan (20.3\%) and South Sudan $(38.8 \%)[21,24,25]$. This disparity may be due to socio-cultural differences and they felt that colostrum would cause their babies to have abdominal crap and have bad sprit and should be discarded. 
This study showed that those mothers who recognized the risk of prelacteal feeding were almost seven times, $(A O R=6.91,95 \% \mathrm{Cl}: 3.002,15.904)$, higher than the counterpart. The report is contrary with study done in Mettu, Sidama district and Raya Kobo district [23, 25, 29]. This may be due to the disparity in, as the mothers are conscious of the disadvantage of Prelacteal Feeding; the mothers are affected by maternal or exhaustive medical illness, CS childbirth and breast-feeding issues, in particular the lack of milk secretions within the first three days of birth. They were concerned about the survival of their child for this cause. This, in fact, leads to the need for pre-lacteal feeding of their babies. The other possible justification may be that, even though mothers have obtained ample information from health facilities, community health workers and mass media about breastfeeding, the influence of local community members, particularly grandparents, may lead them to give prelacteal feeding.

This study showed that infant's birth order between 4-6 were 12.28(AOR: $95 \% \mathrm{Cl}$ : 1.528, 98.639) times more likely to give prelacteal feeding when compared to infant's birth order one. The odds of prelacteal feeding among mothers having $\geq 4$ number of children were nearly five times, (AOR $=5.2,95 \% \mathrm{Cl}: 1.033$, 26.141), higher than, those mothers having $\leq 3$ number of children. This is consistent with study from Harare Region, Eastern Ethiopia [28]. Although contradicting the Nepal report, which was the first order of infant births [31]. This may be due to the gap in; mothers of infants whose births order 4-6 and mothers who have $\geq 4$ number of children were relatively old and multi-para. As a result, compared to younger mothers in this study, relatively elderly and multiparous mothers were more likely to provide prelacteal feeding. Moreover, dominantly influenced by cultural experience and unable to change their behavior as opposed to young people.

In this finding, multipara mothers were 3.56 (AOR: $95 \% \mathrm{Cl}: 1.036,12.227)$ and 10.045 (AOR: $95 \% \mathrm{Cl}: 1.456$, 19.289) times more likely than their counterparts to offer prelacteal feeding and colostrum avoidance. The study coincides with the three African countries in the regions of Burkina Faso, Uganda and South Africa [32] and Tigray region [20]. This may be attributed to cultural resemblance. Multipara mothers are relatively older and are unable to learn about infant feeding and may have a potential to have an effect on cultural traditions. This, in turn, contributes to the need for prelacteal feeding and colostrum avoidance of their infants.

The odds of colostrum avoidance among mothers who gave birth through spontaneous vaginal delivery were three times, (AOR: $95 \% \mathrm{Cl}: 1.245,7.750)$, higher than, those mothers who gave birth via CS. This is contrary to a report conducted in Sudan [25]. This difference is due to the massive missed opportunity and less devotion of skilled attendants to provide essential newborn care, particularly initiation of breast feeding and counseling, since most of the mothers were delivered at the health institution via spontaneous vaginal birth. This means that institutional delivery is not a guarantee of optimum breastfeeding, but rather a high commitment of trained birth attendants delivering critical newborn care.

Among mothers who do not have home health education, the odds of colostrum avoidance were almost five times higher than counterpart (AOR $=5,474,95 \% \mathrm{Cl}: 2,876,10,419)$. The study is consistent with the study carried out in the town of Aksum and the district of Raya Kobo [12, 29]. Intensive health education 
on the possibility of sub-optimal breastfeeding will bring about behavioral improvement, thus enhancing the effective infant feeding practice.

The odds of colostrum avoidance among mothers who have exposure to infant formula advertisement were nearly seven times, $(\mathrm{AOR}=7.476,95 \% \mathrm{Cl}$ : 3.549, 15.752), higher than the counterpart. The study is in line with report from South Sudan [33]. Infant formula advertising has weakened breastfeeding and misled mothers to discard colostrum and to adopt prelacteal feed for their children. This suggests that the vigorous promotion of behavioral modification practices on colostrum feeding has gone undone.

\section{Conclusion}

Early days of newborn feeding mal practice is given one in four infants. This makes breastfeeding practices sub-optimal in the town. Mothers recognizing risks of prelacteal feeding, multipara mothers, having $\geq 4$ number of children and infant's birth order 4-6 were found to be determinants of prelacteal feeding. Likewise, exposure to infant formula advertisement, absence of home to home health education, multipara mothers and spontaneous vaginal birth were the determinants of colostrum avoidance.

\section{List Of Abbreviations}

AOR: $\quad$ Adjusted Odds Ratio

ANC: $\quad$ Ante Natal Care

CS: $\quad$ Cesarian Section

UNICEF: United Nation International Children's Emergency Fund

WHO: $\quad$ World Health Organization

\section{Declarations}

\section{Ethical approval and consent to participate}

Ethical clearance was secured from wollo university, college of medicine and health science to MizanAman town health unit. Permission letters was obtained from Mizan-Aman town health unit and respective kebeles. After giving clear and deep understanding about the aim of the study, written consent was obtained from each respondent before the interview is conducted. Besides, guardian consent was obtained for those participants age below 18. Anonymous data was taken and the confidentiality of participant's information was secured.

\section{Availability of data and materials}


All data generated or analyzed during this study are included in the manuscript and are also available from the corresponding author up on request

\section{Funding}

No external funds were obtained; only institutional support from Mizan-Aman health unit and wollo university.

\section{Acknowledgement}

The author would like to thank Mizan-Aman town health unit staff and community health workers for their kind cooperation. We are also thankful to data collectors and the study participants.

\section{Consent for publication}

Not applicable. Our manuscript does not contain individual person's data in any form such as individual details, images or videos

\section{Competing interests}

The author declare that they have no competing interests.

\section{Author Contribution}

Author contributed to data analysis, drafting and revising the article, gave final approval of the version to be published, and agree to be accountable for all aspects of the work.

\section{References}

1. UNICEF. from the first hour of life: Making the case for improved infant and young child feeding everywhere. New York: UNICEF; 2016

2. WHO/UNICEF. Baby-friendly hospital initiative: revised, updated and expanded for integrated care. Geneva: World Health Organization; 2009. http://www.who.int/nutrition/topics/bfhi/en/index.htm

3. Victoria, C.G., et al., Breastfeeding in the 21st century: epidemiology, mechanisms, and lifelong effect. Lancet, 2016. 387(10017): p. 475-90

4. UNICEF, WHO. Capture the Moment - Early initiation of breastfeeding: The best start for every newborn. New York: UNICEF; 2018

5. UNICEF. from the first hour of life: Making the case for improved infant and young child feeding everywhere. New York: UNICEF; 2016

6. United Nations Inter-Agency Group for Child Mortality Estimation (UN IGME), 'Levels \& Trends in Child Mortality: Report 2019, Estimates developed by the United Nations Inter-Agency Group for Child Mortality Estimation', United Nations Children's Fund, New York, 2019. 
7. WHO. Indicators for assessing Infant and Young Child Feeding Practice Measurement. Conclusions of a consensus meeting held in Washington D.C., USA. 2010; 2.

8. WHO: Global health risks: mortality and burden of disease attributable to selected major risks, 2009. www.who.int/healthinfo/global_burden_disease/GlobalHealthRisks_report

9. Lakati, A.S. et al. The effect of pre-lacteal feeding on full breastfeeding in Nairobi, Kenya. East Afr. J. Public Health. 2010; 7 (3): 258-262.

10. McKenna et al. The practice of prelacteal feeding to newborns among Hindu and Muslim families: J. Midwifery Women's Health. 2009; 54(1):78-81.

11. Temesgen et al. Prelacteal feeding and associated factors in Ethiopia. International Breastfeeding Journal (2018) 13:49 https://doi.org/10.1186/s13006-018-0193-6

12. Weldesamuel et al. Colostrum avoidance and associated factors among mothers having children less than 2 years of age in Aksum town. BMC Res Notes (2018) 11:601 https://doi.org/10.1186/s13104-018-3712-z

13. Haileyesus Gedamu et al. The Prevalence of Traditional Malpractice during Pregnancy, Child Birth, and Postnatal Period among Women of Childbearing Age in Meshenti Town. Hindawi International Journal of Reproductive Medicine Volume 2018, Article ID 5945060, 7 pages https://doi.org/10.1155/2018/5945060

14. The FANTA Project Academy for Educational Development: Ethiopian Profile analysis, 2005.

15. Hussein et al. Breastfeeding performance in Afar regional state, northeastern Ethiopia. BMC Pediatrics (2018) 18:375 https://doi.org/10.1186/s12887-018-1353-y

16. Amele et al. Prelacteal feeding practice and its associated factors among mothers of children age less than 24 months old in Southern Ethiopia. Italian Journal of Pediatrics (2019) 45:15 https://doi.org/10.1186/s13052-019-0604-3

17. FMOH-E (Federal Ministry of Health Ethiopia): National Strategy for Infant and Young Child Feeding Ethiopia. 2004.

18. Government of the Federal Democratic Republic of Ethiopia. National Nutrition Program. June 2013June 2015. Available at https://www.unicef. org/ethiopia/National_Nutrition_Programme.pdf.

19. Central Statistical Agency (CSA) [Ethiopia] and ICF. 2016. Ethiopia Demographic and Health Survey 2016: Key Indicators Report. Addis Ababa, Ethiopia, and Rockville, Maryland, USA. CSA and ICF.

20. Senait Gebreslasie Gebremeskel et al. Magnitude of Prelacteal Feeding and Its Associated Factors among Mothers Having Children Less than One Year of Age: A Community-Based Cross-Sectional Study in Rural Eastern Zone, Tigray, Ethiopia. Hindawi Advances in Public Health Volume 2020, Article ID 4926890, 7 pages https://doi.org/10.1155/2020/4926890

21. Tariku et al. Factors associated with prelacteal feeding in the rural population of northwest Ethiopia. International Breastfeeding Journal (2016) 11:14 DOI 10.1186/s13006-016-0074-9

22. Chea and Asefa. Prelacteal feeding and associated factors among newborns in rural Sidama, south Ethiopia International Breastfeeding Journal (2018) 13:7 https://doi.org/10.1186/s13006-018-0149-x 
23. Wolde et al. Prelacteal feeding and associated factors among mothers having children less than 24 months of age, in Mettu district, Southwest Ethiopia. BMC Res Notes (2019) 12:9 https://doi.org/10.1186/s13104-019-4044-3

24. Argaw et al. Factors associated with prelacteal feeding practices in Debre Berhan district, North Shoa, Central Ethiopia. BMC Nutrition (2019) 5:14 https://doi.org/10.1186/s40795-019-0277-8

25. Justin Bruno Tongun, Mohamedi Boy Sebit, Grace Ndeezi, David Mukunya, Thorkild Tylleskar \& James K. Tumwine (2018) Prevalence and determinants of pre-lacteal feeding in South Sudan: a community-based survey, Global Health Action, 11:1, 1523304, DOI:

10.1080/16549716.2018.1523304

26. Nguyen et al. prelacteal feeding practices in Vietnam: challenges and associated factors. BMC Public Health. 2013; 13(932). http://www.biomedcentral.com/1471-2458/13/932

27. Abdel-Hady and A.-H. El-Gilany. Newborn First Feed and Prelacteal Feeds in Mansoura, Egypt: Biomed Research International. 2014; Article ID 258470, 7 p. http://dx.doi.org/10.1155/2014/258470

28. Bekele yosef, Bezatu Mengistie and Frehiwote Mesfine. Prelacteal Feeding Practice and Associated Factors among Mothers Attending Immunization Clinic in Harare Region Public Health Facilities, Eastern Ethiopia. Open Journal of Preventive Medicine. 2014; 4: 529-534. http://dx.doi.org/10.4236/ojpm.2014.47063

29. Misgan Legesse et al. Factors Associated with Colostrum Avoidance Among Mothers of Children Aged less than 24 Months in Raya Kobo district, North-eastern Ethiopia. Journal of Tropical Pediatrics, 2015, 0, 1-7 doi: 10.1093/tropej/fmv039

30. Gebreyesus $\mathrm{H}$. colostrum avoidance and associated factors among mothers of children aged less than 12 months in kombolcha town. Med. Res. Chron., 2017, 4 (5), 545-559

31. Vishnu Khan, Mandira Adhikari, Kay Sauer and Yun Zhao. Factors associated with the introduction of prelacteal feeds in Nepal: Findings from the Nepal Demographic and HealthSurvey2011.InternationalBreastfeeding Journal.2013;8(9). http://www.internationalbreastfeedingjournal.com/content/8/1/9

32. Engebretsen et al. Early infant feeding practices in three African countries: the PROMISE-EBF trial promoting exclusive breastfeeding by peer counselors. International Breastfeeding Journal.2014;9(19). http://www.internationalbreastfeedingjournal.com/content/9/1/19

33. Bruno Tongun et al. International Breastfeeding Journal (2018) 13:28https://doi.org/10.1186/s13006-018-0170-0

\section{Figures}




\section{percent}

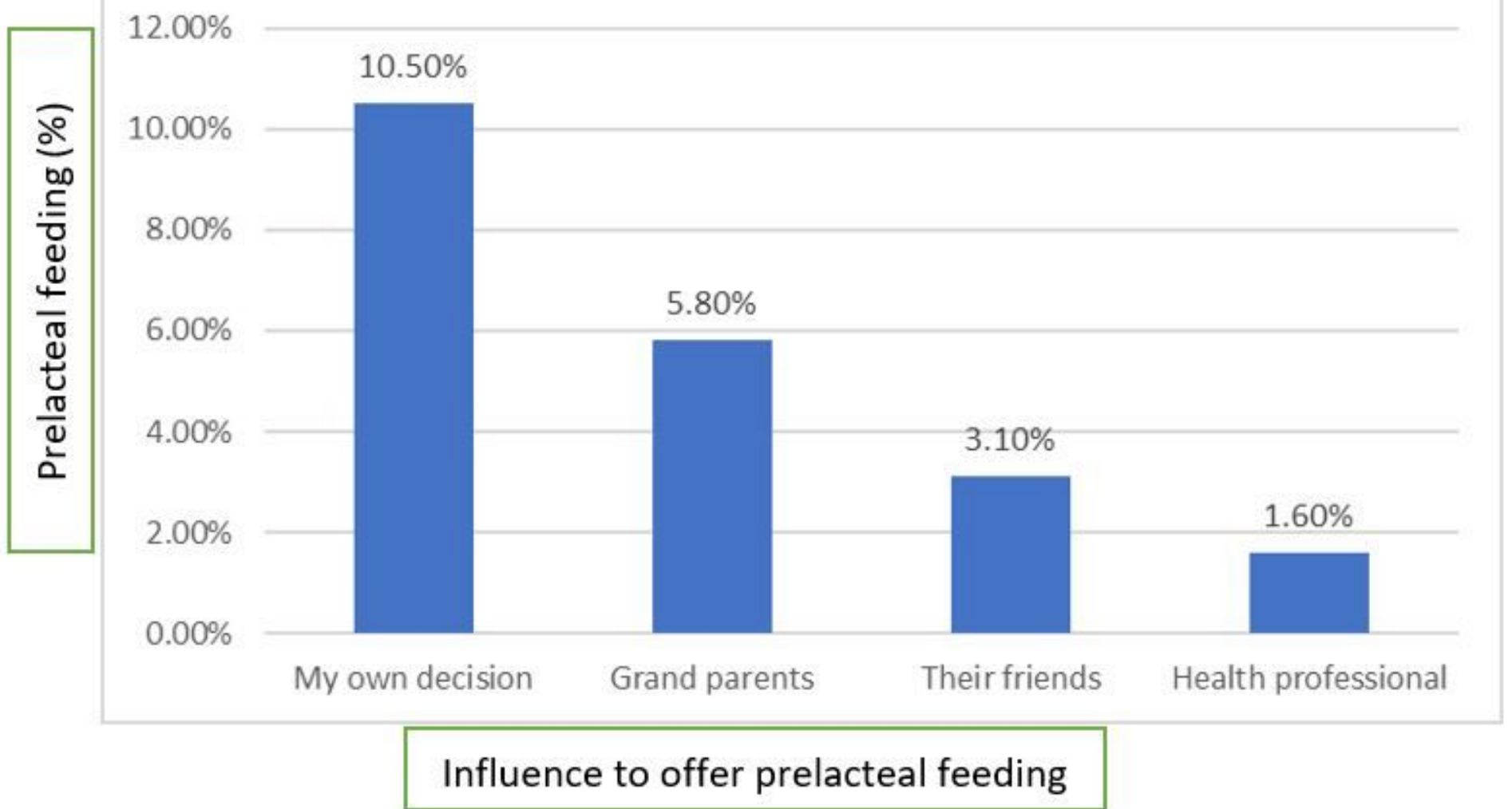

\section{Figure 1}

Influence/advice to provide prelacteal feeding among mothers of children's less than one years of age, Mizan-Aman town, 2020(N=485) 